\title{
How important is the suspended particulate pool for controlling seawater rare earth element distributions?
}

\author{
ED HATHORNE AND MARTIN FRANK ${ }^{1}$ \\ ${ }^{1}$ GEOMAR Helmholtz Centre for Ocean Research Kiel, Germany \\ (ehathorne@geomar.de)
}

Recently reported variations in seawater $\mathrm{Nd}$ isotope compositions on time scales of a few years or even months (Hathorne et al., 2020), are hard to reconcile with a $\mathrm{Nd}$ oceanic residence time on the order of a few hundred years. In the Bay of Bengal and the Andaman Sea variations appear to be linked to the transfer of $\mathrm{Nd}$ and other rare earth elements (REE) from the dissolved or colloidal fraction into the suspended particulate pool. The ratio between unfiltered and filtered seawater REE concentrations (un/filtered ratio) reveals the existence of a large suspended particulate pool around the Andaman Islands with un/filtered ratios of up to 100 for the light REE and 10 for the heavy REE. Off the Sepik river of Papua New Guinea un/filtered ratios around 10 for the LREE and 2 for the HREE have been found while in the Panama Basin un/filtered ratios of 2 for the LREE and near unity for the HREE were observed. The unfiltered concentrations represent the operationally defined dissolved phase plus the labile particulate pool that dissolves in weak hydrochloric acid $(1 \mathrm{~mL}$ per $\mathrm{L}$ at approx. $\mathrm{pH} 2$ ). Even un/filtered ratios of 2 are much larger than those reported in the literature and observed here for more open ocean locations where unfiltered concentrations are only a few percent above those of the filtered samples. This suggests that a seemingly overlooked large suspended particulate pool is an ubiquitous feature near large tropical rivers and may play a globally important role in controlling seawater REE distributions and $\mathrm{Nd}$ isotope compositions. The nature of the particulate pool has been investigated by applying micro-analytical techniques to the filters from different locations. Using new data from off the Congo and Amazon rivers we will assess the potential of the suspended particulate pool to remove and supply the REE dissolved in seawater and the implications of interactions with this pool for other trace elements and nutrients.

Hathorne EC, Frank M and Mohan PM (2020) Front. Mar. Sci. 6:767. doi: 10.3389/fmars.2019.00767 